\title{
Minimally Invasive Microscopic Decompression for Focal Lumbar Spinal Canal Stenosis
}

\author{
AHMED A. ABD ELKHALEK, M.D. and MOHAMED A. THABIT, M.D. \\ The Department of Neurosurgery, Faculty of Medicine, Cairo University
}

\begin{abstract}
Background: Lumbar canal stenosis is the reduction of the surface area of the spinal canal and it is a prevalent disease which has several etiologies. It is a gradual degenerative and aging process. The cut off is the anteroposterior diameter is $12 \mathrm{~mm}$ of the spinal canal below that it is relative stenosis and below $10 \mathrm{~mm}$ it is absolute stenosis. Causes of canal stenosis include congenital and acquired causes (degenerative, spondylolithetic and iatrogenic). It is anatomically classified into central, lateral recess foraminal and extraforaminal. Microscopic unilateral laminectomy for bilateral decompression is a recently developed minimally invasive technique for decompression of the spinal canal with unilateral exposure minimizing soft tissue trauma.
\end{abstract}

Aim of Study: To evaluate the outcome of the procedure and its efficacy in relieving symptoms.

Patients and Methods: A prospective study including 32 patients with single level focal lumbar canal stenosis were included, perioperative assessment with history taking full neurological examination VAS score for pain is done, all had minimally invasive microscopic decompression via a unilateral approach postoperative status complications VAS score was done at 1,3 and $6^{\text {th }}$ months intervals also patient satisfaction was considered.

Results: Thirty two patients were included all had focal type stenosis, 27 at L4, 4 at L3 and one at L5. Sixty percent relieved at first month ,95\% at 3 month and five percent were not satisfied.

Conclusion: The technique is a good option with fast recovery and early ambulation with less post-operative back pain.

Key Words: Lumbar canal stenosis - Microscopic decompression - Minimally invasive approach.

\section{Introduction}

LUMBAR canal stenosis (LCS) is a common spinal problem especially at old age, it may involve a level or more at the lumbar region, it is the reduction

Correspondence to: Dr. Ahmed A. Abd Elkhalek, The Department of Neurosurgery, Faculty of Medicine, Cairo University the size of the spinal canal volume due to several degenerative processes and it is a slowly progressive condition [1-4].

LCS is etiologically classified into developmental and acquired types, acquired LCS include: degenerative causes, combined degenerative and developmental causes, spondylolithetic, post traumatic, iatrogenic and other causes [1-4].

The acquired type is the most commonlyencountered during the clinical practice particularly the degenerative type [1-4].

The LCS is anatomically divided into several subtypes according to the part in the spinal canal that is narrowed i.e. Region of stenosis, this includes: central canal stenosis, lateral recess stenosis, foraminal and extra foraminal stenosis [2-5].

Degenerative canal stenosis is the most clinically encountered subtype and is caused by several factors such as: Discogenic stenosis, facet arthropathy and hypertrophywhich causes lateral recess and foraminal stenosis, ligamintum flavum hypertrophy which causes any type of stenosis (central, lateral recess and foraminal subtypes), the ligament becomes thick and inelastic and becomes buckled during the spinal motion accentuating the spinal stenosis particularly at extension movements $[\mathbf{3 , 4 , 5}$.

The most common symptom of spinal canal stenosis is pain, there are 2 types of pain that are present in LCS: Claudication pain and radicular pain, claudication pain occurs with central canal stenosis and is usually related to posture e.g. prolonged standing and motion, it is usually relieved with flexion posture due to slight increase in the canal diameter, while in lateral recess stenosis or foraminal stenosis the presentation is sciatic pain with effort [4-8]. 
The exact pathophysiology of the condition is not agreeduponwhether it is direct nerve compression or ischemia of the roots, during the investigation of LCS using animal models it has been found that both venous congestion and arterial ischemia causes disruption of the axonal transport of metabolites causing nerve edema, demyelination and degeneration as a final sequela [6-10].

This process affects the sensory fibers more than the motor ones being more fragile, but other authors suggest that the cause of nerve damage is the direct physical compression rather than nerve ischemia [6-10].

LCS is usually diagnosed by the clinical picture and MRI lumbar spine which usually reveals tightening of the canal and the exact level and type of stenosis, the anteroposterior (AP) diameter measuring is one method to classify the LCS at MRI images being a simple way an AP diameter less than $15 \mathrm{~mm}$ up to $12 \mathrm{~mm}$ is called relative stenosis while under $11 \mathrm{~mm}$ is termed absolute stenosis, a more effective measure is the Dural sac area (DSA), the cutoff is area of $75 \mathrm{~mm}^{2}$ more than $75 \mathrm{~mm}^{2}$ is mild stenosis, $50-75 \mathrm{~mm}^{2}$ is moderate stenosis less than $50 \mathrm{~mm}^{2}$ is severe stenosis [8-13].

Usually LCS is managed based on several factors, patient's symptoms and signs, life style and work, Conservative management is usually indicated in mild symptoms, medical comorbidity hindering surgery, or patient is refrained from surgery [10-15].

Surgical intervention is indicated in case of intolerable pain with significant limitation of walking distance, presence of motor deficit or cauda equine syndrome which is not common, surgical procedure include decompressive laminectomy, laminotomy (fenestration) and hemilaminectomy, this can be done via open surgery or via minimal invasive procedure like microscopic or endoscopic surgery, recently a microscopic unilateral approach for bilateral decompression is developed which gives better outcome regarding postoperative back pain [11-15].

\section{Patients and Methods}

This study conducted at Cairo university hospitals from March 2017 till January 2019 and included thirty-two patients all had single level canal stenosis of any age having moderate or severe canal stenosis evaluated on MRI with pain refractory to medical treatment, degenerative type only was evaluated in the study with exclusion of other causes, recurrent cases and patients not amenable to surgery.
All patients included in the study had full history taking and clinical examination: Important points in History included: a. Age, sex. b. Occupation with certain stress on posture, effort and strenuous weight lifting. c. History of claudication distance. Clinical Findings: a. Assessment of general condition of the patient and fitness for surgery. b. Neurological examination: (1) Motor examination including: Power, Superficial \& deep reflexes. (2) Presence of sensory affection (e.g. hypothesia). (3) Nerve root tension tests including: Straight leg raising tests and Femoral nerve stretch test. Radiological investigations: X-Ray lumbosacral spine with dynamic views (to exclude instability) and MRI of the lumbosacral spine were performed for all patients.

Surgical procedure: Patient is positioned prone, localization of the desired level is done using $\mathrm{x}$ ray image, A midline linear skin incision of approximately $3 \mathrm{~cm}$ is made, fascia is opened using a scalpel and a fascial flap using scissors is made and retracted, The muscles from one side are separated from their attachments, the interlaminar space exposed. Laminotomy is performed using a surgical microscope, the upper lamina are partially removed (fenestrated) till the upper edge of the ligamentum flavum is exposed. The basal part of the spinous process of the caudal half of the cranial lamina and a small cranial portion of the caudal lamina are removed with a high-speed drill or kerrison rongeursthen this is followed by flavectomy. If there is bilateral stenosis, then the contralateral lamina is undercut with a high-speed drill or kerrison rongeurs leaving the ligamentum flavum in place as protection for the dural sac and the nerve root then the contralateral decompression is performed first this will also need some tilting of the surgical table towards the contralateral side for better visualization. When the ligament is exposed clearly it is dissected from the dura and removed. With recognition of the inner aspect of the pedicle on the contralateral side this confirms the adequate decompression of the contralateral side. Then an ipsilateral side foraminotomy is done and closure in layers is performed. A confirmatory image localization is done intraoperatively when the desired lamina is reached before performance of the procedure.

Postoperative treatment: Antibiotics, analgesics, I.V fluids and neurotropic drugs were routinely used for all the patients. Follow-up and outcome: a- Full neurological examination was performed to all patients to detect improvement or deterioration of the neurological condition. Improvement 
of back pain and radicular lower limb pain were assessed by VAS back pain score and VAS leg pain score. Patients were discharged within 24- 96 hours depending on the patient condition with followup and evaluation after one and three months at the outpatient clinic.

\section{Results}

Thirty two patients were included all had focal type stenosis. The age ranges in this study was from 44 years till 73 years with mean age of 58.7 . The study included 22 males and 10 females. 22 patients suffered low back pain \& neurogenic claudication while 10 patients had neurogenic claudication only (without back pain). Duration of symptoms ranged from 18 to 32 months with mean of 22 months. Preoperative VAS score for pain results showed in Table (1). VAS after 1 month of surgery (Table 2) and 3 months (Table 3). Twentyseven patients had LCS at L4 level, four at L3 and one at L5. Sixty percent were satisfied at first month, $95 \%$ at 3 months and five percent were not satisfied (Chart 1).
Table (1): Duration of symptoms ranged from 18 to 32 months with mean of 22 months. Preoperative VAS score for pain.

\begin{tabular}{lccc}
\hline VAS score (0-10) & Minimum & Maximum & Mean \\
\hline Bach pain & 6 & 9 & 7.5 \\
Leg pain & 6 & 9 & 7 \\
\hline
\end{tabular}

Table (2): VAS after 1 month of surgery.

\begin{tabular}{lccc}
\hline VAS score & Minimum & Maximum & Mean \\
\hline Bach pain & 2 & 4 & 3 \\
Leg pain & 3 & 4 & 6 \\
\hline
\end{tabular}

Table (3): VAS after 3 months surgery.

\begin{tabular}{lccc}
\hline VAS score & Minimum & Maximum & Mean \\
\hline Bach pain & 1 & 3 & 2 \\
Leg pain & 2 & 4 & 3 \\
\hline
\end{tabular}

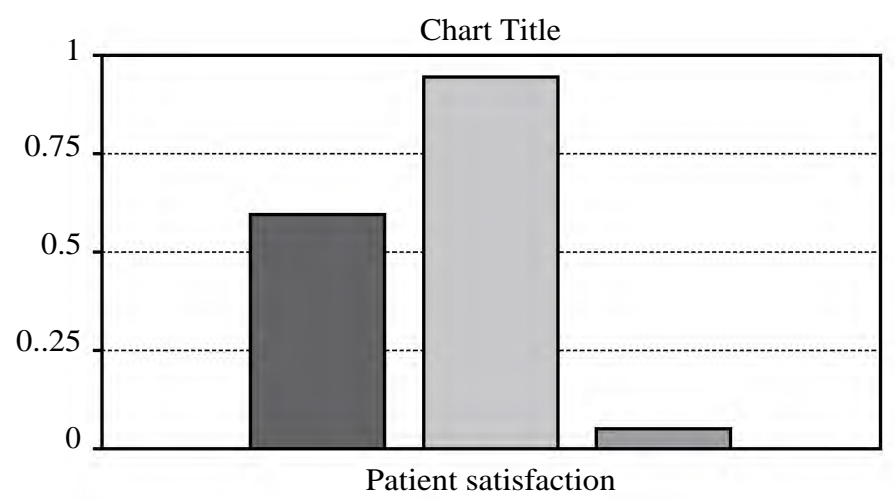

One month $\square 3$ months $\square$ Unsatisfied

Chart (1): Twenty-seven patients had LCS at L4 level, four at L3 and one at L5. Sixty percent were satisfied at first month, $95 \%$ at 3 months and five percent were not satisfied.
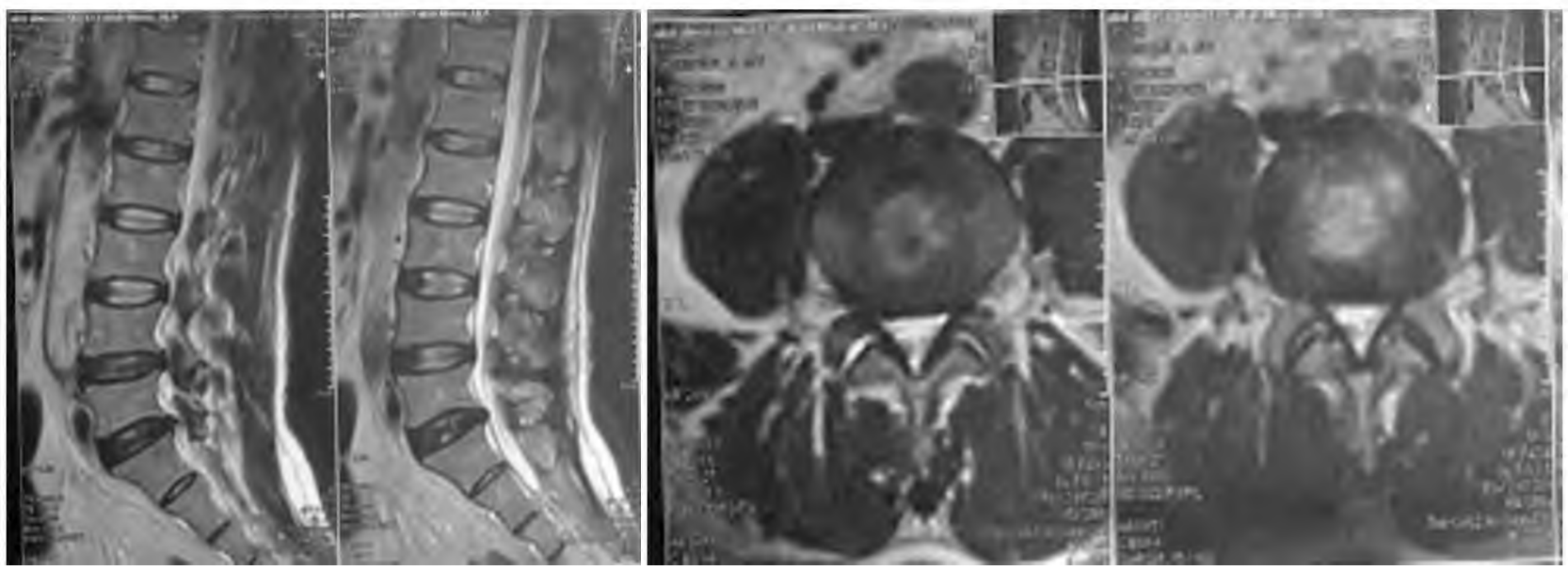

Fig. (1): Preoperative MRI of a male patient 60 years old, Complaining of LBP and Lt neurogenic claudication one year of increased intensity, tingling of dorsum of Lt thigh, VAS Leg pain is 8 and VAS back pain is 7. By Examination: FMP, hyposthesia along L5 root, MRI: L4 lumbar canal stenosis, operated L4 bilateral decompression via unilateral laminotomy, Postoperative: Pain improved. VAS back pain score is 3 and VAS leg pain is 4 then after 1 month, VAS back pain is 2 and VAS leg pain is 1. 

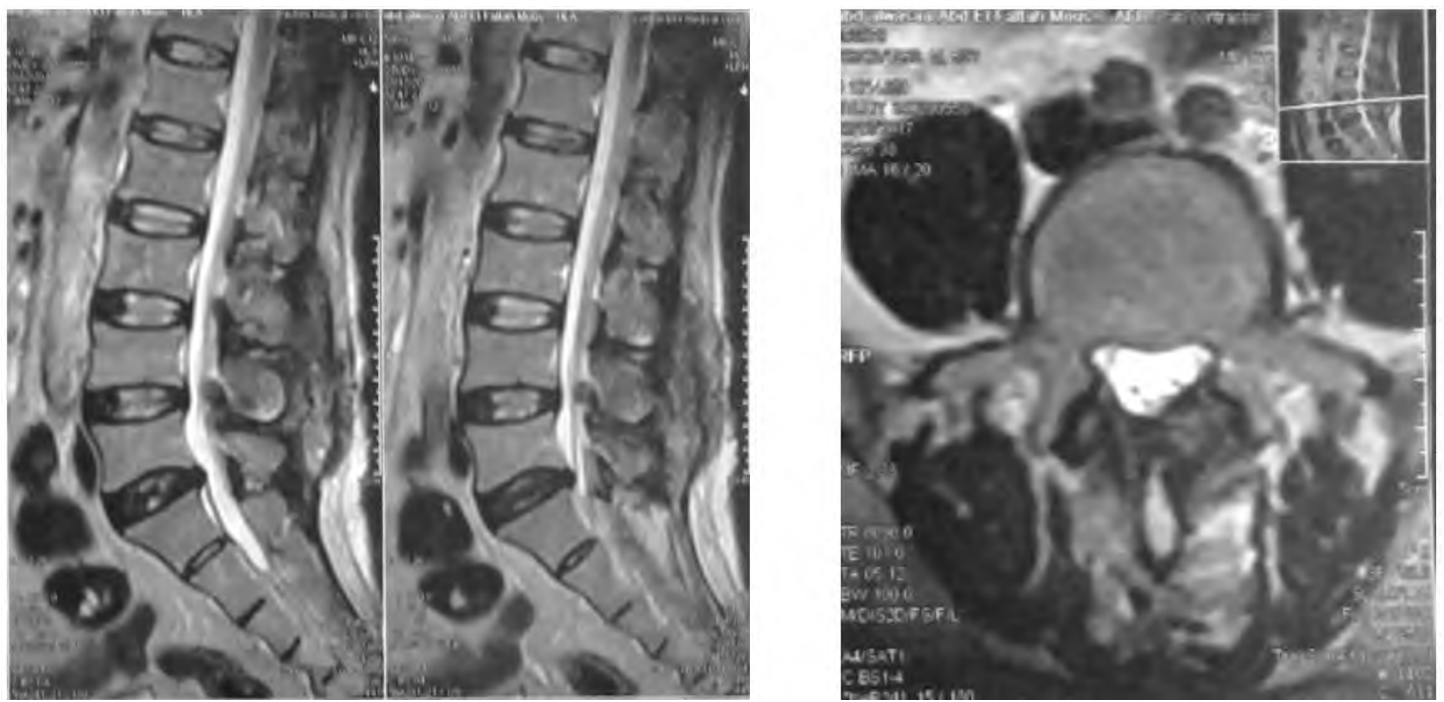

Fig. (2): Postoperative MRI after 3 months for the same patient in Fig. (1).

\section{Discussion}

In this study, we operated thirty-two patients with single level stenosis most commonly affecting L4 level with VAS outcome improvement at 3 months of 3 for leg pain and 2 for back pain. Average operative time was 42 minutes and average hospital stay was 1.2 days.

Rahman et al., [16] in their study reported the results of minimally invasive versus the classic laminectomy for decompression in LCS in 126 patients, 38 cases underwent bilateral decompression using a unilateral minimally invasive approach and 88 with open laminectomy. The age and number of levels were not specified. They finally stated that the minimally invasive group had less operating time, less blood loss, fewer complications, and better mobility in immediate postoperative period.

Cho et al., in their series operated upon 40 minimally invasive procedures and 30 open laminectomy the average operating time was $259 \mathrm{~min}$ utes and hospital stay was 4 days compared to 7 days in open laminectomy cases [17].

Yaman et al., reported the records of 40 patients who were surgically treated for LCS by different methods, which were studied retrospectively. The patients were grouped into two groups for the surgical procedure.one group were done by an open laminectomy and the other using a minimally invasive one sided approach [18].

VAS was used to assess low back and leg pain preoperatively and postoperatively at 1,6 , and 12 months. The two groups were compared in respect to the time of surgery, recovery and hospital stay.
They concluded that bilateral decompression using a unilateral approach is as good as laminectomy moreover without any instability effect, this also gives sufficient decompression in the degenerative LCS and improves patient recovery after surgery [18].

According to the postoperative outcome and patient's satisfaction we relied upon the VAS score of leg pain and back pain, we compared the difference in both scores preoperatively, 1 month and 3 months after surgery.

We found the VAS score of leg and back pain had been showing significant improvement after 1 and 3 months postoperatively with increased patient's satisfaction after 3 months of operations.

Thomé et al., reported that clinical outcomes after a minimally invasive approach were the same as open laminectomy, the follow-up period was minimum of 1 year. [19] Usman et al., reported in their study on unilateral laminotomy for bilateral decompression the average operative time was 69 minutes and hospital stay of 4.7 days the compared 30 cases with 30 open laminectomy who had longer operative time and hospital stay [20].

\section{Conclusion:}

Microsurgicalunilateral approach for the management of LCS allows for good and safe decompression of the lumbar spinal canal in patients with lumbar stenosis. It is also allowed for a major improvement in the outcome factors during a follow-up period of six months with no instability effect. Knowledge of the surgeon and his experience of the approach is crucial in reducing the operative time. 


\section{References}

1- MOORE K.L., DALLEY A.F. and AGUR A.M.R.: Back. Clinically oriented anatomy (sixth edition), Lippincott Williams and Wilkins, 439-507, 2010.

2- ANNE M.R. AGUR and ARTHUR F. DALLEY II: Back. Grant's Atlas of Anatomy-LWW, 16-50, 2016.

3- RICHARD DRAKE PH.D., A. WAYNE VOGL PH.D., ADAM W.M. MITCHELL MBBS FRCS, RICHARD TIBBITTS and PAUL RICHARDSON: Grays Atlas of Anatomy, 3e. Back, 68-81, 2015.

4- EDWARD C. BENZEL: Benzel Spine Surgery, 3e: 1-81, 2012.

5- NIKOLAI BOGDUK and STEPHEN M. ENDRES: Clinical Anatomy of the Lumbar Spine and Sacrum $5^{\text {th }}$, e. 4146, 2012.

6- DRAKE R.L., VOGL A.W. and MITCHELL W.M.: Anatomy of the back. Gray's anatomy for students (third edition). Elsevier Churchill Livingstone, 51-120, 2015.

7- JOHN T. HANSEN and FRANK H. NETTER: Netter's Cinical Anatomy, (Third Edition), 49-86, 2014.

8- ROSS J.S. and BELL G.R.: Spine imaging. In: Herkowitz H.N, Garfin S.R, Eismont F.J. et al. (eds). The spine (sixth edition). Elsevier Saunders, 187-2209, 2011.

9- PARKE W.W., BONO C.M. and GARFIN S.R.: Applied anatomy of the spine. In: Herkowitz H.N, Garfin S.R, Eismont F.J., et al. (eds). The spine (sixth edition). Elsevier Saunders, 15-53, 2011.

10- KUOFI H.S., BADAWI M. and FATANI J.A.: Ligaments associated with lumbar intervertebral foramina. J. Anat., 156: 177-183, 2003.

11- BOGDUK N.: The innervation of the lumbar spine. Spine 2008; 8:286-293.

12- CROCK H.V.: Normal and pathological anatomy of the lumbar spinal nerve root canals. J. Bone Joint Surg. (Br.), 63: 487-490, 2001
13- ROSNER M.K. and CAMPBELL V.A.: Treatment of disc disease of the lumbar spine. In Winn H.R. (ed). Youmans neurological surgery (sixth edition). Elsevier Saunders, 2919-2922, 2011.

14- ARNOLDI C.C., et al.: Lumbar spinal stenosis and nerve root entrapment syndromes. Definition and classification. ORR, 115: 4-5, 2011.

15- LEE C.K., et al.: Lateral lumbar spinal canal stenosis: Classification, pathological anatomy and surgical decompression. Spine, 13 (3): 313-20, 2005.

16- RAHMAN M., SUMMERS L., RICHTER B., MIMRAN R. and JACOB R.: Comparison of Techniques for Decompressive Lumbar Laminectomy: The Minimally Invasive versus the "Classic" Open Approach. Minim Invas Neurosurg, 51: 100-105, 2008.

17- CHO D.Y., LIN H.L., LEE W.Y. and LEE H.C.: Splitspinous process laminotomy and discectomy for degenerative lumbar spinal stenosis: A preliminary report. J. Neurosurg Spine, 6: 229-239, 2007.

18- YAMAN O., OZDEMI N., DAGLI A.T., ACAR E., DALBAYRAK S. and TEMIZ C.: A comparison of bilateral decompression via unilateral approach and classic laminectomy in patients with lumbar spinal stenosis: A retrospective clinical study. Turk Neurosurg, 25 (2): 239-45, 2015.

19- THOME C., ZEVGARIDIS D., LEHETA O., BAZNER H., POCKLER-SCHONIGER C., WOHRLE J. and SCHMIEDEK P.: Outcome after less-invasive decompression of lumbar spinal stenosis: A randomized comparison of unilateral laminotomy, bilateral laminotomy, and laminectomy. J. Neurosurg Spine, (2): 129-141, 2005.

20- USMAN M., ALI M., KHANZADA K., ISHAQ M., NAEEM-UL-HAQ R. and ALI M.: Unilateral approach for bilateral decompression of lumbar spinal stenosis: A minimal invasive surgery. J. Coll. Physicians Surg. Pak, 23: 852-856, 2013.

\section{الجراحات الميكروسكوبية المحلدودة من ناحية واحلدة العمية الميكية

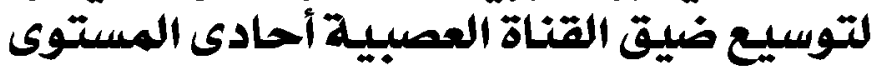

$$
\begin{aligned}
& \text { المقدمة: ضيق العصبية القطنية يحدث للمرضى مع التقدم فى العمر حيث يشتكى المريض من العرج العصبى وخصوصاً عند المشى } \\
& \text { لفترات طويلة. } \\
& \text { الإهداف: المقارنة بين نتائج الجراحة المجهرية والجراحة القياسية فى علاج ضيق القناة العصبية القطنية. } \\
& \text { الوسـائل : إجراء الجراحات المجهرية لاثثتى وثلاثقن حالة تعانى من ضيق القناة العصبية القطينية، وتمت متابعة الحالات بعد الجراحة وبعد } \\
& \text { ثبهر وثلاث شهون. }
\end{aligned}
$$

$$
\text { النتائج: وجد أى إجراء الجراحة المجهرية أفضل من الجراحات القياسية في علاج ضيق القناة العصبية القطنية. }
$$

